\title{
Chemoenzymatic Generation of Phospholipid Membranes Mediated by Type I Fatty Acid Synthase
}

\author{
Satyam Khanal, ${ }^{\dagger}$ Roberto J. Brea, ${ }^{\dagger}$ Michael D. Burkart*,†, Neal K. Devaraj*, ${ }^{\dagger}$ \\ 'Department of Chemistry and Biochemistry, University of California, San Diego, La Jolla, CA 92093, USA.
}

\begin{abstract}
The de novo formation of lipid membranes from minimal reactive precursors is a major goal in synthetic cell research. In nature, the synthesis of membrane phospholipids is orchestrated by numerous enzymes, including fatty acid synthases and membrane-bound acyltransferases. However, these enzymatic pathways are difficult to fully reproduce in vitro. As such, the reconstitution of phospholipid membrane synthesis from simple metabolic building blocks remains a challenge. Here, we describe a chemoenzymatic strategy for lipid membrane generation that utilizes a soluble bacterial fatty acid synthase (cgFAS I) to synthesize palmitoyl-CoA in situ from acetyl-CoA and malonyl-CoA. The fatty acid derivative spontaneously reacts with a cysteine-modified lysophospholipid by native chemical ligation (NCL), affording a non-canonical amidophospholipid that self-assembles into micron-sized membrane-bound vesicles. To our knowledge, this is the first example of reconstituting phospholipid membrane formation directly from acetyl-CoA and malonyl-CoA precursors. Our results demonstrate that combining the specificity and efficiency of a type I fatty acid synthase with a highly selective bioconjugation reaction provides a biomimetic route for the de novo formation of membrane-bound vesicles.
\end{abstract}

All living organisms use phospholipid membranes to control the exchange of materials with the extracellular matrix, isolate and protect sensitive chemical reactions, and maintain homeostasis inside cells. ${ }^{1}$ Furthermore, cells require phospholipid membranes for energy production, membrane protein synthesis, and cell signaling. ${ }^{2,3}$ Phospholipids are enzymatically generated by membrane-bound acyl-transferases as part of the Kennedy lipid synthesis pathway. ${ }^{4,5}$ The fatty acids needed for these biochemical reactions are in turn made by fatty acid synthases (FASs). FASs are ubiquitous proteins that catalyze the synthesis of fatty acids in a highly efficient manner through modularization of enzymatic functions and the use of carrier-mediated substrate shuttling. ${ }^{6}$ Through coordinated action, the different enzymatic modules of the FAS biosynthesize an elongated acyl chain of a specific length. Typical fatty acid products of FASs are palmitic, stearic and oleic acid. ${ }^{7-9}$

Drawing inspiration from the biochemical pathways for phospholipid synthesis, various research groups have devised strategies for the bottom-up construction of phospholipid membranes. ${ }^{10-12}$ Although recent studies have shown that phospholipids can be generated abiotically using chemical coupling reactions, ${ }^{13,14}$ the alkyl chains are typically synthesized in advance and provided externally. Currently, there are no known biomimetic strategies that synthesize phospholipids de novo by coupling in situ formed fatty acid tails with single-chain amphiphiles. Instead of externally adding alkyl species, we sought to harness a FAS for the formation of activated fatty acids from simple metabolic building blocks such as acetyl-CoA and malonyl-CoA. Subsequently, the activated fatty acids could chemically react with lipid precursors to form phospholipid membranes. Such a chemoenzymatic scheme would better mimic biological phospholipid synthesis compared to previous synthetic strategies and would enable the use of very short chain acyl-CoAs to drive membrane formation. Here, we employ a bacterial type I FAS 
bioRxiv preprint doi: https://doi.org/10.1101/2021.04.21.440816; this version posted April 22, 2021. The copyright holder for this preprint (which was not certified by peer review) is the author/funder, who has granted bioRxiv a license to display the preprint in perpetuity. It is made available under aCC-BY-NC-ND 4.0 International license.

(cgFAS I), in combination with native chemical ligation (NCL), to spontaneously generate membrane-forming synthetic phospholipids from simple water-soluble fatty acid precursors (Figure 1). Our chemoenzymatic approach enables de novo membrane formation, that is membrane formation in the absence of preexisting membranes. Chemoenzymatic phospholipid formation may provide simpler strategies to generate membrane compartments in synthetic cells, ${ }^{10,13,15,16}$ support the advancement of methods for reconstituting membrane proteins, ${ }^{17,18}$ and facilitate the synthesis of natural and non-canonical lipids. ${ }^{19}$

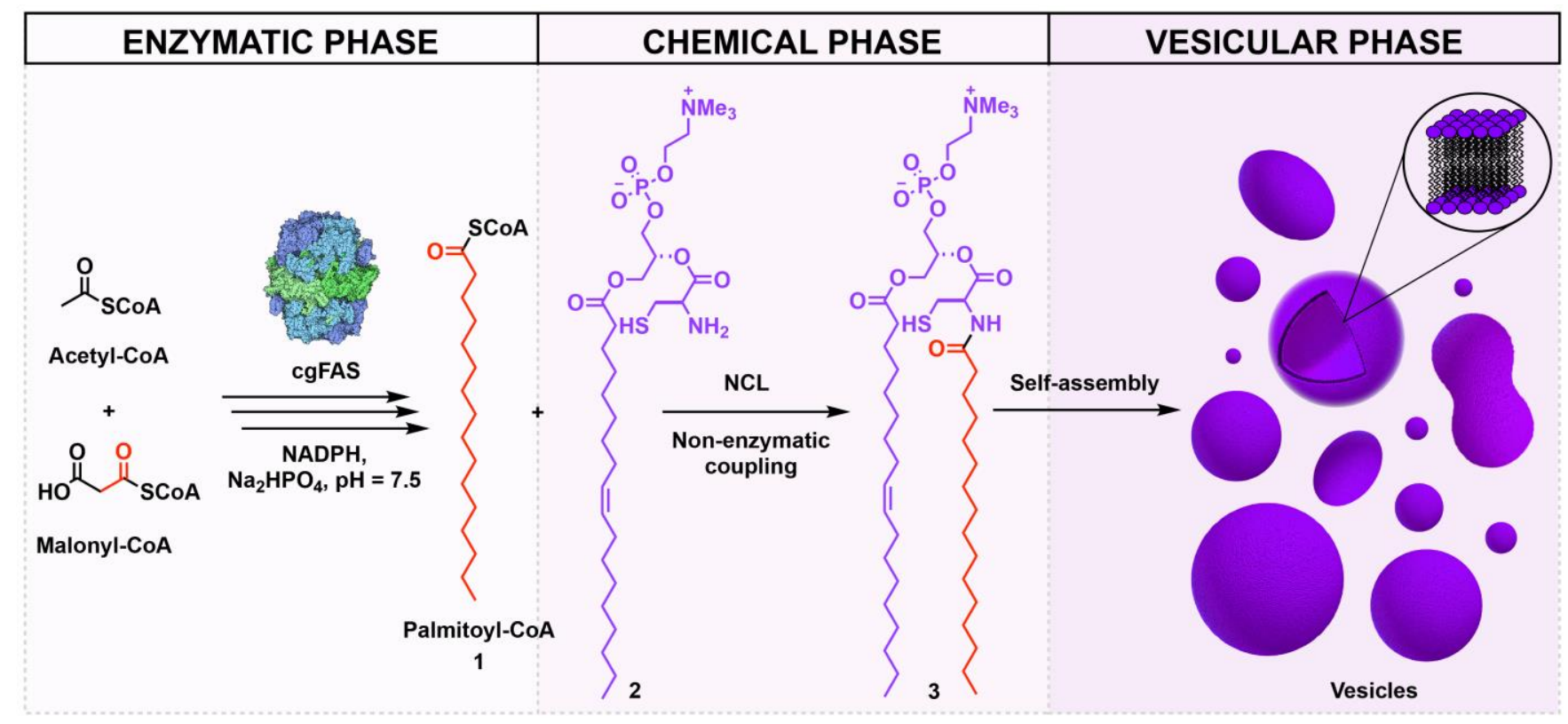

Figure 1. Schematic representation of FAS-mediated chemoenzymatic phospholipid synthesis. A bacterial type I FAS synthesizes palmitoylCoA 1 in situ using acetyl-CoA, malonyl-CoA and NADPH. 1 subsequently reacts with cysteine-modified lysophospholipid 2 via native chemical ligation (NCL) to form phospholipid $\mathbf{3}$, which spontaneously self-assembles into membrane-bound vesicles.

We first identified an appropriate FAS for the in situ formation of activated fatty acids. While type II FASs are comprised of multiple enzymes working in a coordinated fashion, type I FASs consist of a single multi-enzyme complex with catalytic domains that interact with each other in a cooperative manner to form fatty acids. ${ }^{6}$ Through iterative cycles, a type I FAS utilizes acetyl-CoA and malonyl-CoA to produce medium-chain fatty acids in a stoichiometric fashion (Figure 2A). We considered that a type I FAS would be an ideal enzyme for our system as it would require reconstituting a single multi-domain protein. Additionally, some type I FASs, such as yeast and bacterial FASs, produce fatty acyl-CoA as their final product. ${ }^{7}$ As coenzyme A is a good leaving group, we reasoned that the bacterial type IFAS would be an appropriate enzyme for generating activated fatty acid products that could be efficiently coupled with appropriate thioester-reactive lysophospholipids to form non-canonical phospholipids in situ. We chose to work with type I FAS B from Corynebacterium glutamicum (cgFAS I) as it has been shown to primarily produce palmitoyl-CoA ${ }^{20}$ (Figure $2 \mathrm{~A}$ ) and has been efficiently expressed in E. coli. ${ }^{21}$ 


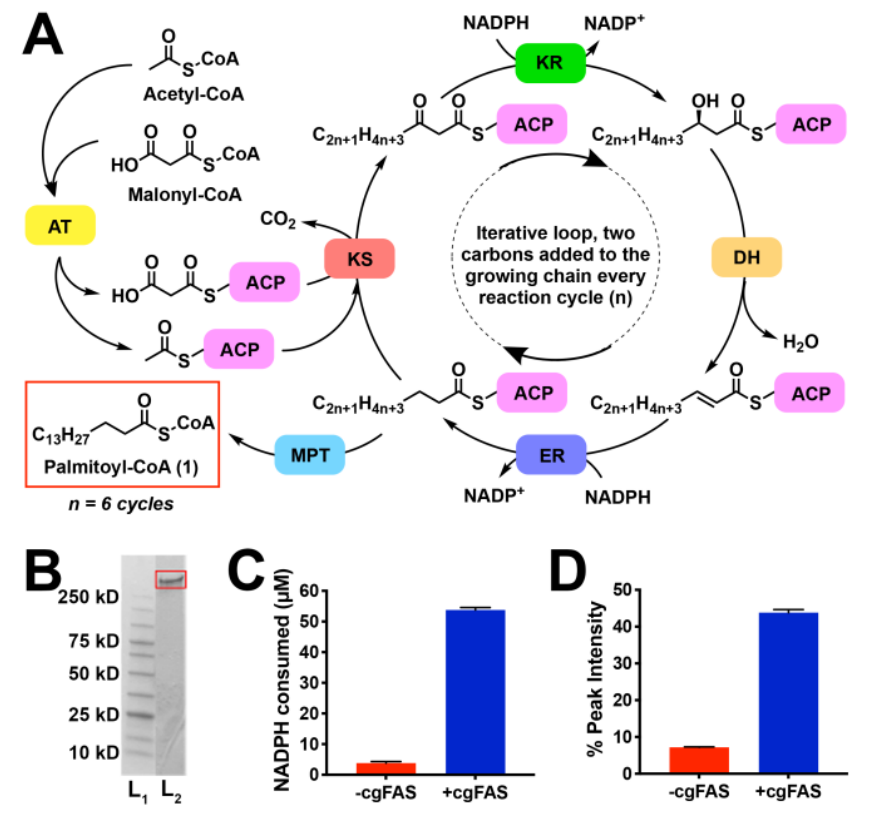

Figure 2. In situ synthesis of palmitoyl-CoA 1 mediated by bacterial type I FAS (cgFAS). A) Schematic representation of the iterative fatty acid elongation cycle. Malonyl-palmitoyltransferase (MPT) transfers the final palmitoyl moiety to a CoA molecule to form 1 [AT: acyl transferase; ACP: acyl carrier protein; KS: ketosynthase; KR: ketoreductase; DH: dehydratase; ER: enoyl reductase]. B) SDS-PAGE analysis of the His-tagged cgFAS after FPLC purification. Lane $1\left(\mathrm{~L}_{1}\right)$ : ladder; Lane 2 ( $\left.\mathrm{L}_{2}\right)$ : purified His-tagged cgFAS (325 kDa). C) NADPH consumption assay analysis, verifying cgFAS activity. D) GC-MS FAME analysis of the cgFAS-catalyzed formation of 1 over $1 \mathrm{~h}$.

$\mathrm{N}$-terminal His ${ }_{-}$-tagged type I cgFAS was expressed in E. coli and purified by adapting a previously published procedure. ${ }^{8}$ The integrity of the protein, as well as its oligomeric state, were verified using size exclusion chromatography (SEC) on a fast protein liquid chromatography (FPLC) column (Figure 2B). The fractions were then subjected to a nicotinamide adenine dinucleotide phosphate (NADPH) consumption assay to verify cgFAS activity (Figure 2C). First, we treated cgFAS I (100 nM) with acetyl-CoA $(100 \mu \mathrm{M})$, malonyl-CoA $(700 \mu \mathrm{M})$ and NADPH $(1 \mathrm{mM})$ in $1 \mathrm{mM}$ phosphate $\left(\mathrm{Na}_{2} \mathrm{HPO}_{4} / \mathrm{NaH}_{2} \mathrm{PO}_{4}\right)$ buffer, $\mathrm{pH} 7.4$ containing $1 \mathrm{mM}$ tris(2-carboxyethyl)phosphine hydrochloride (TCEP) at $37^{\circ} \mathrm{C}$. Subsequently, we monitored NADPH oxidation to $\mathrm{NADP}^{+}$over time by the decrease in fluorescence at $470 \mathrm{~nm}$. The amount of NADPH consumed was verified by making a calibration curve using commercially available NADPH (Figure S2B). In agreement with previous reports, we observed that palmitoyl-CoA 1 was the major product of the cgFAS I-catalyzed reaction. ${ }^{20,21}$ Using gas chromatography-mass spectrometry (GC-MS) after fatty acid methyl ester (FAME) formation (Figure 2D, Figure S3), we observed that 1 comprised $93 \%$ of the total fatty acid species formed. Moreover, using the NADPH consumption assay together with high performance liquid chromatography-mass spectrometry (HPLC-MS), we observed that $41 \mu \mathrm{M}$ of $\mathbf{1}$ was produced by the cgFAS I-mediated reaction, corresponding to $40.6 \%$ yield.

We next proceeded to select an appropriate thioester-reactive lysophospholipid for chemical coupling with cgFAS I-synthesized palmitoyl-CoA. We had previously prepared a novel class of cysteine-modified lysophospholipids that can undergo spontaneous acylation by NCL reaction with long-chain thioesters. ${ }^{10,16,22}$ We therefore hypothesized that cysteine-modified lysolipids would react by NCL with palmitoyl-CoA 1 generated in situ by cgFAS I. As a test, we synthesized cysteine-modified lysophospholipid 2 (Scheme S1A) and demonstrated NCL coupling with commercially available palmitoyl-CoA, forming phospholipid 3 (Figure S4B). Briefly, we treated lysophospholipid $2(1 \mathrm{mM})$ with palmitoyl-CoA $(1 \mathrm{mM})$ in $10 \mathrm{mM}$ phosphate $\left(\mathrm{Na}_{2} \mathrm{HPO}_{4} / \mathrm{NaH}_{2} \mathrm{PO}_{4}\right)$ buffer, $\mathrm{pH} 7.4$ containing $10 \mathrm{mM}$ TCEP at $37^{\circ} \mathrm{C}$. Phospholipid formation was followed using HPLCMS combined with evaporative light-scattering detection (ELSD) and corroborated by chemically characterized standards 
bioRxiv preprint doi: https://doi.org/10.1101/2021.04.21.440816; this version posted April 22, 2021. The copyright holder for this preprint (which was not certified by peer review) is the author/funder, who has granted bioRxiv a license to display the preprint in perpetuity. It is made available under aCC-BY-NC-ND 4.0 International license.

(Scheme S1B, Figure S4). Using calibration curves, we determined that $820 \mu \mathrm{M}$ of phospholipid 3 was formed after $3 \mathrm{~h}$, corresponding to a yield of $82 \%$.

In previous work, we have observed that amphiphilic species are preferentially acylated by amphiphilic reactants, likely promoted by co-assembly in micelles or membranes. ${ }^{13,15,22}$ To better understand the role self-assembly plays in the formation of the phospholipid product, we investigated the reactivity of lysophospholipid 2 with non-amphiphilic small-chain thioesters. Malonyl- and acetyl-CoA were selected as reactive thioester partners with $\mathbf{2}$. Although both substrates contain a reactive thioester moiety that can react by NCL with cysteine-modified lysophospholipid $\mathbf{2}$, the absence of a long-chain hydrophobic tail precludes assembly into structures such as micelles. Therefore, we anticipated a difference in their reactivity with $\mathbf{2}$ in comparison to the previously tested palmitoyl-CoA $\mathbf{1}$. As expected, when we attempted to react $\mathbf{2}$ with malonyl- or acetyl-CoA under our standard NCL reaction conditions, we were unable to detect product formation (Figure S5).

To determine the ability of non-canonical phospholipid $\mathbf{3}$ to form membrane-bound vesicles, microscopy studies were performed. Neither palmitoyl-CoA 1 nor lysophospholipid 2 formed membranes in aqueous solution. On the other hand, phospholipid 3 readily formed membrane-bound assemblies when hydrated (Figure 3). Lipid vesicles were initially identified by phase-contrast (Figure 3A) and fluorescence microscopy using the membrane-staining dye BODIPY-FL DHPE (Figure 3B, Figure S6A). Under these conditions, vesicles of 1-10 $\mu \mathrm{m}$ diameter were observed after hydration and tumbling of 3 in phosphate buffer, pH 7.4 at $37{ }^{\circ} \mathrm{C}$ for $1 \mathrm{~h}$. Transmission electron microscopy (TEM) also corroborated the formation of vesicular structures (Figure 3C). The encapsulation ability of the phospholipid vesicles was demonstrated by hydrating a thin lipid film of $\mathbf{3}$ in the presence of 8-hydroxypyrene-1,3,6-trisulfonic acid (HPTS), a highly polar fluorescent dye, followed by removal of excess dye by spin-filtration and vesicle characterization using fluorescence microscopy (Figure 3D, Figure S6B).

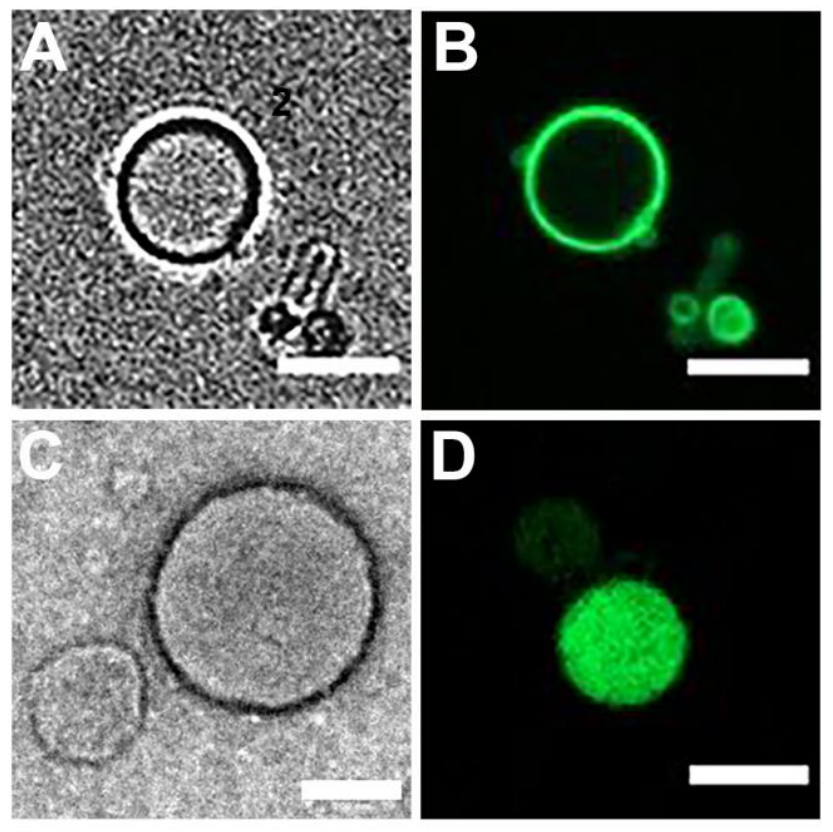

Figure 3. Characterization of phospholipid 3 vesicular structures. A) Phase-contrast microscopy image of membrane-bound vesicles resulting from the self-assembly of $\mathbf{3}$. Scale bar denotes $5 \mu \mathrm{m}$. B) Fluorescence microscopy image of vesicles formed by hydration of a thin film of $\mathbf{3}$. Membranes were stained with 0.1 mol \% BODIPY-FL DHPE. Scale bar denotes $5 \mu \mathrm{m}$. C) TEM image of negatively stained vesicles of 3. Scale bar denotes $100 \mathrm{~nm}$. D) Fluorescence microscope image demonstrating the encapsulation of HPTS in vesicles of 3. Scale bar denotes $5 \mu \mathrm{m}$. 
bioRxiv preprint doi: https://doi.org/10.1101/2021.04.21.440816; this version posted April 22, 2021. The copyright holder for this preprint (which was not certified by peer review) is the author/funder, who has granted bioRxiv a license to display the preprint in perpetuity. It is made available under aCC-BY-NC-ND 4.0 International license.

Having characterized the individual enzymatic and chemical reactions, we next explored combining enzymatic palmitoyl-CoA $\mathbf{1}$ synthesis with chemical phospholipid $\mathbf{3}$ synthesis in a one-pot reaction (Figure 4). Briefly, we added lysophospholipid 2 (400 $\mu \mathrm{M})$ to $10 \mathrm{mM}$ phosphate $\left(\mathrm{Na}_{2} \mathrm{HPO}_{4} / \mathrm{NaH}_{2} \mathrm{PO}_{4}\right)$ buffer, $\mathrm{pH} 7.4$ containing cgFAS I $(1 \mu \mathrm{M})$, acetyl-CoA $(1 \mathrm{mM})$, malonyl-CoA $(1 \mathrm{mM})$ and NADPH $(10 \mathrm{mM})$ along with $10 \mathrm{mM}$ (TCEP) at $37^{\circ} \mathrm{C}$. Phospholipid formation was followed using HPLC-MSELSD measurements. Optimization of the reaction conditions enabled rapid coupling between cgFAS I generated $\mathbf{1}$ and $\mathbf{2}$. The one-pot reaction afforded the corresponding phospholipid $\mathbf{3}$ as the prominent product within $30 \mathrm{~min}$ (Figure 4A). All of lysophospholipid 2 was consumed in less than 4 h (Figure 4 B) to afford $367 \mu \mathrm{M}$ of phospholipid 3 . After 30 min of reaction, small vesicular structures were detected by fluorescence microscopy using BODIPY-FL DHPE (Figure S7A). After leaving the reaction tumbling overnight at $37^{\circ} \mathrm{C}$, we observed larger vesicles in the range of 1-2 $\mu \mathrm{m}$ in diameter (Figure 4C, Figure S7B).

We next investigated the one-pot chemoenzymatic formation of membranes in the presence of biologically relevant cell membrane components, including cholesterol ${ }^{23}$, ionic small molecules such as guanidine hydrochloride $(\mathrm{GuHCl})^{24-26}$, and shortchain alkanols such as decanol ${ }^{27}$. We added cholesterol $(400 \mu \mathrm{M}), \mathrm{GuHCl}(400 \mu \mathrm{M})$ and 1-decanol $(400 \mu \mathrm{M})$ to the one-pot in situ chemoenzymatic reaction forming phospholipid 3. We observed that the additives did not perturb the formation of phospholipid 3 membranes, and, if anything, led to the formation of larger vesicles. Vesicles were stable over $48 \mathrm{~h}$ at $37^{\circ} \mathrm{C}$, as observed by fluorescence microscopy using BODIPY-FL DHPE (Figure 4D).
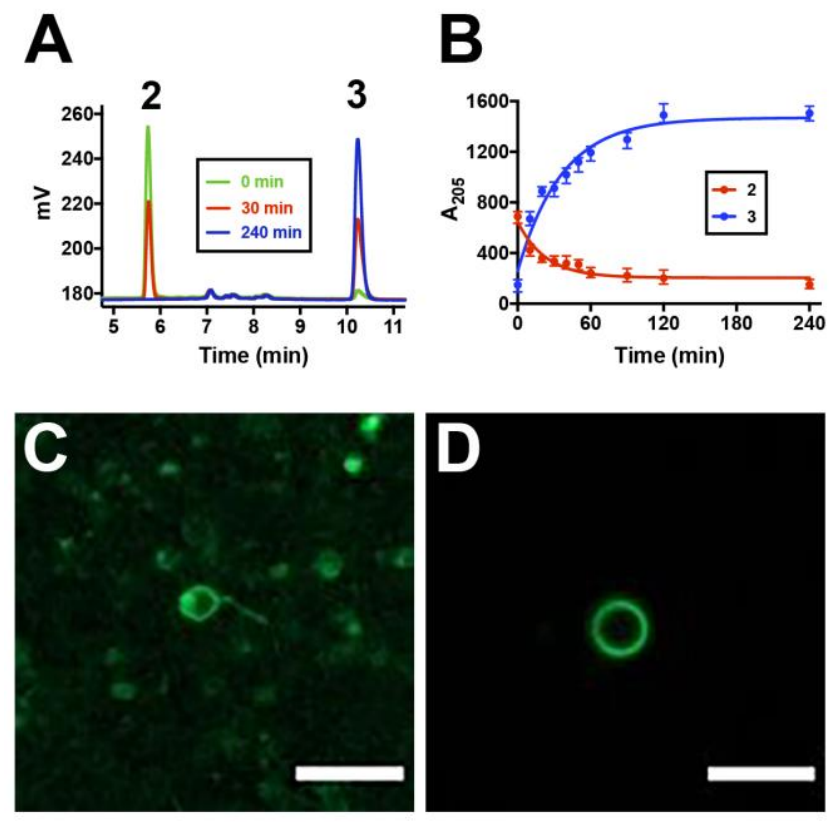

Figure 4. One-pot chemoenzymatic formation and self-assembly of phospholipid 3. A) HPLC traces corresponding to the NCL-based synthesis of phospholipid $\mathbf{3}$ from enzymatically generated $\mathbf{1}$ and lysophospholipid 2. B) Kinetic curves of lysophospholipid $\mathbf{2}$ consumption and phospholipid 3 formation during one-pot synthesis. C) Fluorescence microscopy image of phospholipid 3 vesicles after 4 h of chemoenzymatic reaction. D) Fluorescence microscopy image of chemoenzymatically formed vesicles of $\mathbf{3}$ in the presence of GuHCl, decanol and cholesterol. Membranes were stained with 0.1 mol \% BODIPY-FL DHPE. Scale bar denotes $5 \mu \mathrm{m}$.

In summary, we have developed a chemoenzymatic route to synthesize non-canonical phospholipids from water-soluble precursors. We showed that palmitoyl-CoA generated in situ by bacterial type I FAS effectively couples with a cysteine-modified lysophospholipid. The resulting phospholipid synthesis triggers de novo formation of membrane-bound vesicles. Given our approach, there should be flexibility to diversify the lipid species generated in the reaction. Even though we utilized cgFAS I to selectively produce palmitoyl-CoA, the use of fatty acid synthases from other organisms could enable the formation of a 
bioRxiv preprint doi: https://doi.org/10.1101/2021.04.21.440816; this version posted April 22, 2021. The copyright holder for this preprint (which was not certified by peer review) is the author/funder, who has granted bioRxiv a license to display the preprint in perpetuity. It is made available under aCC-BY-NC-ND 4.0 International license.

diverse array of fatty acyl-CoA species, which could be subsequently coupled to reactive lysophospholipids to give several non-canonical lipid species. For instance, many bacterial FAS are known to synthesize terminally branched iso-, anteiso-, or omega-alicyclic fatty acids from branched, short-chain carboxylic acid precursors such as methylmalonyl-CoA., ${ }^{7,28}, \mathrm{We}$ plan on utilizing the in situ synthesis of diverse phospholipid species to facilitate investigations of how lipid membrane composition affects vesicle assembly, growth and division.

\section{AUTHOR INFORMATION}

\section{Corresponding Authors}

Neal K. Devaraj - Department of Chemistry and Biochemistry, University of California, San Diego, CA 92093, USA; orcid.org/00000002-8033-9973; Email: ndevaraj@ucsd.edu

Michael D. Burkart - Department of Chemistry and Biochemistry, University of California, San Diego, CA 92093, USA; orcid.org/0000-0002-4472-2254; Email: mburkart@ucsd.edu

\section{Authors}

Satyam Khanal - Department of Chemistry and Biochemistry, University of California, San Diego, CA 92093, USA; orcid.org/00000001-5720-0044; Email: skhanal@ucsd.edu

Roberto J. Brea - Department of Chemistry and Biochemistry, University of California, San Diego, CA 92093, USA; orcid.org/00000002-0321-0156; Email: rbreafernandez@ucsd.edu

Notes

The authors declare no competing financial interest.

\section{ACKNOWLEDGMENT}

This material is based upon work supported by the National Science Foundation (EF-1935372) and the Department of Defense (Army Research Office) through the MURI program (W911NF-13-1-0383). We sincerely thank Prof. Jay Keasling (University of California, Berkeley) for generously providing us the plasmid for the type I FAS B from Corynebacterium glutamicum (cgFAS I). We thank Prof. Itay Budin (University of California, San Diego) and Prof. Martin Grininger (Goethe University Frankfurt) for helpful discussions. Satyam Khanal acknowledges support from a Roger Tsien Fellowship through UCSD.

\section{REFERENCES}

(1) Alberts, B.; Johnson, A.; Lewis, J.; Raff, M.; Roberts, K.; Walter, P. Molecular Biology of the Cell (4 ${ }^{\text {th }}$ Edition), Garland Science, New York (USA), 2002.

(2) Sunshine, H.; Iruela-Arispe, M. L. Membrane Lipids and Cell Signaling. Curr. Opin. Lipidol. 2017, 28, 408-413.

(3) Goñi, F. M. The Basic Structure and Dynamics of Cell Membranes: An Update of the Singer-Nicolson Model. BBA - Biomembranes 2014, $1838,1467-1476$.

(4) Yao, J.; Rock, C. O. Phosphatidic Acid Synthesis in Bacteria. BBA - Mol. Cell Biol. L. 2013, 1831, 495-502.

(5) Yamashita, A.; Sugiura, T.; Waku, K. Acyltransferases and Transacylases Involved in Fatty Acid Remodeling of Phospholipids and Metabolism of Bioactive Lipids in Mammalian Cells. J. Biochem. 1997, 122, 1-16.

(6) Maier, T.; Leibundgut, M.; Boehringer, D.; Ban, N. Structure and Function of Eukaryotic Fatty Acid Synthases. Q. Rev. Biophys. 2010, 43, $373-422$.

(7) Schweizer, E.; Hofmann, J. Microbial Type I Fatty Acid Synthases (FAS): Major Players in a Network of Cellular FAS Systems. Microbiol. Mol. Biol. Rev. 2004, 68, 501-517. 
bioRxiv preprint doi: https://doi.org/10.1101/2021.04.21.440816; this version posted April 22, 2021. The copyright holder for this preprint (which was not certified by peer review) is the author/funder, who has granted bioRxiv a license to display the preprint in perpetuity. It is made available under aCC-BY-NC-ND 4.0 International license.

(8) Rittner, A.; Paithankar, K. S.; Drexler, D. J.; Himmler, A.; Grininger, M. Probing the Modularity of Megasynthases by Rational Engineering of a Fatty Acid Synthase Type I: Probing the Modularity of Megasynthases by Rational Engineering of a Fatty Acid Synthase Type I. Protein Sci. 2019, 28, 414-428.

(9) Chen, A.; Re, R. N.; Burkart, M. D. Type II Fatty Acid and Polyketide Synthases: Deciphering Protein-Protein and Protein-Substrate Interactions. Nat. Prod. Rep. 2018, 35, 1029-1045.

(10) Brea, R. J.; Cole, C. M.; Devaraj, N. K. In Situ Vesicle Formation by Native Chemical Ligation. Angew. Chem. Int. Ed. 2014, 53, 1410214105.

(11) Matsuo, M.; Ohyama, S.; Sakurai, K.; Toyota, T.; Suzuki, K.; Sugawara, T. A Sustainable Self-Reproducing Liposome Consisting of a Synthetic Phospholipid. Chem. Phys. Lipids 2019, 222, 1-7.

(12) Xiong, F.; Lu, L.; Sun, T. Y.; Wu, Q.; Yan, D.; Chen, Y.; Zhang, X.; Wei, W.; Lu, Y.; Sun, W. Y.; Li, J. J.; Zhao, J. A Bioinspired and Biocompatible Ortho-Sulfiliminyl Phenol Synthesis. Nat. Commun. 2017, 8, 15912.

(13) Budin, I.; Devaraj, N. K. Membrane Assembly Driven by a Biomimetic Coupling Reaction. J. Am. Chem. Soc. 2012, 134, $751-753$.

(14) Flores, J.; White, B. M.; Brea, R. J.; Baskin, J. M.; Devaraj, N. K. Lipids: Chemical Tools for Their Synthesis, Modification, and Analysis. Chem. Soc. Rev. 2020, 49, 4602-4614.

(15) Brea, R. J.; Bhattacharya, A.; Devaraj, N. K. Spontaneous Phospholipid Membrane Formation by Histidine Ligation. Synlett 2017, 28, 108112.

(16) Bhattacharya, A.; Brea, R. J.; Devaraj, N. K. De Novo Vesicle Formation and Growth: An Integrative Approach to Artificial Cells. Chem. Sci. 2017, 8, 7912-7922.

(17) Cole, C. M.; Brea, R. J.; Kim, Y. H.; Hardy, M. D.; Yang, J.; Devaraj, N. K. Spontaneous Reconstitution of Functional Transmembrane Proteins during Bioorthogonal Phospholipid Membrane Synthesis. Angew. Chem. Int. Ed. 2015, 54, 12738-12742.

(18) Brea, R. J.; Cole, C. M.; Lyda, B. R.; Ye, L.; Prosser, R. S.; Sunahara, R. K.; Devaraj, N. K. In Situ Reconstitution of the Adenosine A2A Receptor in Spontaneously Formed Synthetic Liposomes. J. Am. Chem. Soc. 2017, 139, 3607-3610.

(19) Iwasaki, Y.; Yamane, T. Enzymatic Synthesis of Structured Lipids. Adv. Biochem. Eng. Biotechnol. 2004, 90, 151-171.

(20) Radmacher, E.; Alderwick, L. J.; Besra, G. S.; Brown, A. K.; Gibson, K. J. C.; Sahm, H.; Eggeling, L. Two Functional FAS-I Type Fatty Acid Synthases in Corynebacterium glutamicum. Microbiology 2005, 151, 2421-2427.

(21) Haushalter, R. W.; Groff, D.; Deutsch, S.; The, L.; Chavkin, T. A.; Brunner, S. F.; Katz, L.; Keasling, J. D. Development of an Orthogonal Fatty Acid Biosynthesis System in E. coli for Oleochemical Production. Metab. Eng. 2015, 30, 1-6.

(22) Seoane, A. A.; Brea, R. J.; Fuertes, A.; Podolsky, K. A.; Devaraj, N. K. Biomimetic Generation and Remodeling of Phospholipid Membranes by Dynamic Imine Chemistry. J. Am. Chem. Soc. 2018, 140, 8388-8391.

(23) Krause, M. R.; Regen, S. L. The Structural Role of Cholesterol in Cell Membranes: From Condensed Bilayers to Lipid Rafts. Acc. Chem. Res. 2014, 47, 3512-3521.

(24) Douliez, J. P.; Houinsou-Houssou, B.; Fameau, A. L.; Novales, B.; Gaillard, C. Self Assembly of Anastomosis-like Superstructures in Fatty Acid/Guanidine Hydrochloride Aqueous Dispersions. J. Colloid Interface Sci. 2010, 341, 386-389.

(25) Fameau, A. L.; Houinsou-Houssou, B.; Ventureira, J. L.; Navailles, L.; Nallet, F.; Novales, B.; Douliez, J. P. Self-Assembly, Foaming, and Emulsifying Properties of Sodium Alkyl Carboxylate/Guanidine Hydrochloride Aqueous Mixtures. Langmuir 2011, $27,4505-4513$.

(26) Douliez, J. P.; Houssou, B. H.; Fameau, A. L.; Navailles, L.; Nallet, F.; Grélard, A.; Dufourc, E. J.; Gaillard, C. Self-Assembly of Bilayer Vesicles Made of Saturated Long Chain Fatty Acids. Langmuir 2016, 32, 401-410.

(27) Suryabrahmam, B.; Agrawal, A.; Raghunathan, V. A. Fluid-Fluid Coexistence in Phospholipid Membranes Induced by Decanol. Soft Matter 2020, 16, 9002-9005.

(28) Kaneda, T. Fatty Acids of the Genus Bacillus: An Example of Branched Chain Preference. Bacteriol. Rev. 1977, 41, $391-418$.

(29) Kaneda, T. Iso- and Anteiso-Fatty Acids in Bacteria: Biosynthesis, Function, and Taxonomic Significance. Microbiol. Rev. 1991, 55, 288302. 
bioRxiv preprint doi: https://doi.org/10.1101/2021.04.21.440816; this version posted April 22, 2021. The copyright holder for this preprint (which was not certified by peer review) is the author/funder, who has granted bioRxiv a license to display the preprint in perpetuity. It is made available under aCC-BY-NC-ND 4.0 International license. 